\title{
Better Destination Memory in Females
}

\author{
Mohamad El Haj', 2,3, Philippe Allain', Joanna Lucenet ${ }^{5}$, and André Ndobo' \\ ' Nantes Université, Univ Angers, Laboratoire de Psychologie des Pays de la Loire (LPPL - EA 4638), F-44000 Nantes, France \\ 2 Unité de Gériatrie, Centre Hospitalier de Tourcoing, Tourcoing, France \\ ${ }^{3}$ Institut Universitaire de France, Paris, France \\ ${ }^{4}$ Laboratoire de Psychologie des Pays de la Loire, LPPL EA 4638, SFR Confluences, UNIV Angers, Nantes Université, Maison de la \\ recherche Germaine Tillion, 5 bis Boulevard Lavoisier, 49045 Angers Cedex 01 \\ ${ }^{5}$ Laboratoire de psychologie de l'université de Bordeaux EA 4139 \\ ABSTRACT
}

\section{KEYWORDS}

destination memory

episodic memory

gender

own-gender bias

Destination memory refers to the ability to remember to whom one has sent information. The current study investigated gender differences in destination memory. Female and male participants were asked to tell proverbs to pictures depicting faces of female and male celebrities. Participants were later asked to decide to whom each proverb had been previously told. Results showed better destination memory (regardless of the destination's gender) in female participants than in male participants, a performance that was significantly correlated with verbal episodic memory. However, no own-gender bias was observed, as both female and male participants demonstrated similar memory for female and male destinations. Taken together, our findings suggest a relationship between females' superiority in destination memory and their better verbal episodic memory. The absence of an own-gender bias in destination memory is interpreted an evolutionary need to maintain social contacts with all genders.

\section{INTRODUCTION}

Destination memory is the ability to remember to whom one has sent information (e.g., "Did I send that email to my colleague $X$ or Y?"; El Haj et al., 2014; El Haj et al., 2016; Gopie et al., 2010; Gopie \& MacLceod, 2009). Destination memory, a component of the episodic memory system (El Haj et al., 2014; El Haj et al., 2016; Gopie et al., 2010; Gopie \& MacLeod, 2009), has been found to be closely associated with social processing (El Haj \& Miller, 2018). For instance, destination memory has been found to be influenced by familiarity (El Haj, Omigie et al., 2015) and the emotional state of one's interlocutors (El Haj, Fasotti et al., 2015; El Haj, Raffard et al., 2015). Bearing these considerations in mind, the aim of the current study was to assess whether destination memory is also influenced by the gender of one's interlocutors. Such an assessment may reveal gender differences in the ability to remember to whom information has been previously told, and, more broadly, potential differences in memory for social interactions.

Research has demonstrated that, generally speaking, males perform better than females in visuo-spatial working memory tasks (Cornoldi \& Vecchi, 2004). However, one study has demonstrated that, although males performed better than females on a paper-andpencil task assessing object-location memory, no differences were observed on an augmented reality task assessing this type of memory (Munoz-Montoya et al., 2019). Also, the participants' performance in this study was significantly correlated with anxiety. While males may perform better than females on visuo-spatial working memory tasks, the reverse can be observed for verbal memory (Ullman et al., 2008). Research suggests better verbal memory in females than in males, probably because females express more affect connection, and factual elaboration during retrieval than males (Fivush, 2011; Fivush et al., 2011; Fivush \& Nelson, 2004; Grysman, Fivush et al., 2016; Grysman, Merrill et al., 2016). In other words, compared to males, females tend to retrieve more detailed, more elaborated, more emotionally expres-

Corresponding author: Mohamad El Haj, Faculté de Psychologie, LPPL Laboratoire de Psychologie des Pays de la Loire, Université de Nantes, Chemin de la Censive du Tertre, BP 81227, 44312 Nantes Cedex 3, France.

E-mail:mohamad.elhaj@univ-nantes.fr 
sive memories (Grysman, 2017). The emotional expressivity in females during retrieval can be influenced by endogenous levels of sex hormones (Wassell et al., 2015).

Also, females tend to outperform males in tasks involving facial recognition (McBain et al., 2009; Rehnman \& Herlitz, 2007). Research has even demonstrated an own-gender bias in females, that is, females tend to perform at a higher level with female faces than with male faces (Steffens et al., 2013; Wright \& Sladden, 2003). On the other hand, males do not appear to show a corresponding own-gender bias for male faces (Megreya et al., 2011; Rehnman \& Herlitz, 2006). The owngender bias, as observed in females, has been interpreted as reflecting females' greater social interest, which is specifically directed towards other females (Loven et al., 2011). Support for this account comes from studies suggesting that females form longer-lasting and closer relationships with other females than males do between each other (Sherman et al., 2000). Another theory is that females may be more interested in female faces than in male faces due to the high value placed by society on female attractiveness (Cross et al., 1971; Ellis et al., 1973).

To summarize, we assessed whether destination memory is influenced by the gender of one's interlocutors. We thus carried out a study in which female and male participants were asked to tell proverbs to pictures depicting faces of female and male celebrities. Participants were later asked to indicate to whom each proverb had been told. We expected to find better destination memory in female than in male participants. We also expected better destination memory for female than for male faces in female participants. Finally, we investigated the potential relationship between destination memory and verbal episodic memory in female and male participants in light of research attributing differences in face processing to a general superiority of females in verbal episodic memory (Herlitz \& Lovén, 2013).

\section{METHODS}

\section{Participants}

Sixty graduate/undergraduate psychology students participated in the study ( 31 females, $M_{\text {age }}=23.17, S D=.99$ ). The sample size was based on previous research on destination memory (El Haj, 2017; El Haj, Omigie, et al., 2015). The sample size was also determined as the maximal number of participants who were willing to participate to the study between February and April 2019. Participants were recruited specifically for this study. Prior to inclusion, all participants gave their written informed consent in accordance with the principles laid down by the Helsinki Declaration. Exclusion criteria were a history of psychiatric, neurological, or learning disorders.

\section{Materials}

The study included a test of verbal episodic memory in order to control for memory performance as well as a test of destination memory. Note that, in the same session, participants were assessed with the verbal memory test followed by the destination memory test.

\section{VERBAL EPISODIC MEMORY}

Verbal episodic memory was assessed using the task from Grober and Buschke (1987). We used this task as it was reliably validated in the French population (Van der Linden et al., 2004). In this task, participants had to retain 16 words, each describing an item belonging to a different semantic category. After a $20 \mathrm{~s}$ distraction phase, they had to recall as many words as they could, the maximum score being 16 points. The mean score of the participants in the current study was 12.33 points $(S D=3.14)$.

\section{DESTINATION MEMORY}

To assess destination memory, we used 24 proverbs (e.g., "the pen is mightier than the sword," "when in Rome do as the Romans do," "send a thief to catch a thief") and 24 color pictures depicting faces of celebrities (e.g,, Michael Jackson, Donald Trump, Barack Obama). The proverbs and the celebrity pictures were chosen according to their familiarity, in light of research showing that in everyday life, people tend to relay familiar information to familiar destinations (El Haj, Omigie, et al., 2015). The degree of familiarity of the proverbs and the celebrity pictures was evaluated in a separate sample of eight males and eight females on a four-point scale ( $1=$ unfamiliar, 2 = somewhat familiar, 3 = familiar, 4 = very familiar). The mean age of this sample was 22.75 ( $S D=.87)$, Welch's $t$ test demonstrated no significant differences between this mean and that of the main sample, $t(21)=1.54$, $\mathrm{p}$ $=.14$. This separate sample reported a familiarity score of above 3 for the proverbs and the celebrity pictures. No significant differences were detected between males and females $\left(M_{\text {males }}=3.44, S D=.21, M_{\text {females }}\right.$ $=3.52, S D=.16, Z=.46, p>.1)$. Twelve of the celebrity pictures were male and 12 were female.

\section{Procedure}

Destination memory assessment and response recording were controlled with the Psychopy software package coupled with a laptop computer and a $15 \mathrm{in.} \mathrm{LCD} \mathrm{display.} \mathrm{Assessment} \mathrm{included} \mathrm{a} \mathrm{study} \mathrm{phase,} \mathrm{an}$ interpolated phase, and a recognition phase.

\section{STUDY PHASE}

The study phase included 24 trials, each beginning with a $1 \mathrm{~s}$ white fixation cross followed by a proverb presented in white Times New Roman 40-point font below a $(12 \times 12 \mathrm{~cm})$ colored picture of a celebrity. After telling each proverb to its correspondent destination, the participants pressed any key to continue with another white fixation cross for $1 \mathrm{~s}$. This procedure was repeated until the participants had told 24 proverbs to the 12 male and 12 female celebrity pictures. Proverbs were told with no time limit. The correspondence between proverbs and destinations, as well as the order of presentation of male versus female destinations, were randomized for all participants. Prior to the study phase, participants were informed that they would tell proverbs to a picture of a celebrity and that their memory for the destination would be tested in a later session. Immediately after the study phase, participants performed the interpolated phase in which they read aloud strings of three-digit numbers for $1 \mathrm{~min}$. 


\section{RECOGNITION PHASE}

After the interpolated phase, participants proceeded to the recognition phase in which the previously exposed 24 proverbs and celebrity pictures were paired and presented in random order: 12 intact pairs (six proverb-male celebrities pairs + six proverb-female celebrities pairs) + 12 repairings (six proverb-male celebrities pairs + six proverb-female celebrities pairs). Proverb-celebrity pairs were presented one at a time, with the proverb below the celebrity picture. For each pair, the participants had to decide whether they had previously told that proverb to that celebrity picture or not. No time limit was imposed for responses, which constituted pressing a green key for the "yes" responses, and a red key for the "no" responses. After each response, a blank screen was displayed for $250 \mathrm{~ms}$, followed by the next test trial.

\section{DEPENDENT VARIABLE}

Destination memory was assessed as the proportion of hits (correct "yes" responses) minus the proportion of false alarms (incorrect "yes" responses), as recommended for analyzing recognition memory (Snodgrass \& Corwin, 1988).

\section{RESULTS}

We first compared the differences in destination memory in female versus male participants for female versus male destinations. We then compared the differences in verbal episodic memory, as assessed by the Grober and Buschke (1987) task, between female and male participants. Finally, we assessed Pearson correlations between destination memory and verbal episodic memory in female and male participants. Parametric tests were applied after verifying the normality of the data distribution with the Kolmogorov-Smirnov test, $D(60)=.123, p=.026$.

\section{Better General Destination Memory but No Own-Gender Bias in Female Participants}

Recognition scores, as depicted in Figure 1, were submitted to a repeated-measures analysis of variance (ANOVA) with participant gender (female, male) as a between-subject variable and destination gender (female, male) as a within-subject variable. The analysis showed a significant effect of participant gender, $F(1,58)=5.48, p<.05, \eta^{2}$ $=.09$. Female participants showed better general destination memory than male participants, with respective means of $.86(S D=.15)$ and .78 $(S D=.17)$. To assess whether the significant effect of participant gender on destination memory is influenced by verbal episodic memory, we carried out an analyis of covariance (ANCOVA) with destination memory as the dependent variable, gender as the main factor, and verbal episodic memory as the covariate. The analysis demonstrated a significant effect of participant gender, $F(1,57)=13.50, p<.001, \eta^{2}$ $=.41$. Thus, the effect of participant gender on destination memory increased after controlling for verbal episodic memory. The interaction between destination memory and episodic memory was significant, $F(1,57)=10.01, p=.002, \eta^{2}=.38$, suggesting that episodic memory may influence destination memory. The intercation between gender and episodic memory was also significant, $F(1,57)=11.30, p=.001, \eta^{2}$ $=.40$, suggesting that gender may influence episodic memory.

The effect of destination gender was not significant, $F(1,58)=1.57$, $p>.1, \eta^{2}=.03$, revealing similar destination memory for female and male celebrities, with respective means of $.84(S D=.16)$ and $.80(S D$ $=.17)$. The interaction between participant gender and destination gender was not significant, $F(1,58)=.04, p>.1, \eta^{2}=.01$, revealing no own-gender bias either in female or male participants.

\section{Better Verbal Episodic Memory in Female Participants than in Male Participants}

The analyses showed better verbal episodic memory in female than in male participants, with respective means of $13.10(S D=2.71)$ and $11.41(S D=3.43), t(58)=2.12, p<.05$.

\section{Significant Correlations Between Destination Memory and Verbal Episodic Memory}

Significant correlations were observed between verbal episodic memory and destination memory both in female $(r=.57, p<.01)$ and male participants $(r=.46, p<.05)$.

\section{DISCUSSION}

The current study assessed gender differences in destination memory. Our first hypothesis was confirmed, as better general destination memory was observed in female than in male participants. Our second hypothesis was not confirmed, as no own-gender bias was observed either in female or in male participants. However, better verbal episodic memory was observed in female than in male participants, and significant correlations were observed between verbal episodic memory and destination memory in both samples. These findings suggest a relationship between females' superiority in destination memory and their better verbal episodic memory.

By demonstrating better destination memory in female than in male participants, our findings contribute to the literature suggesting gender differences in memory and face processing. Typically, females

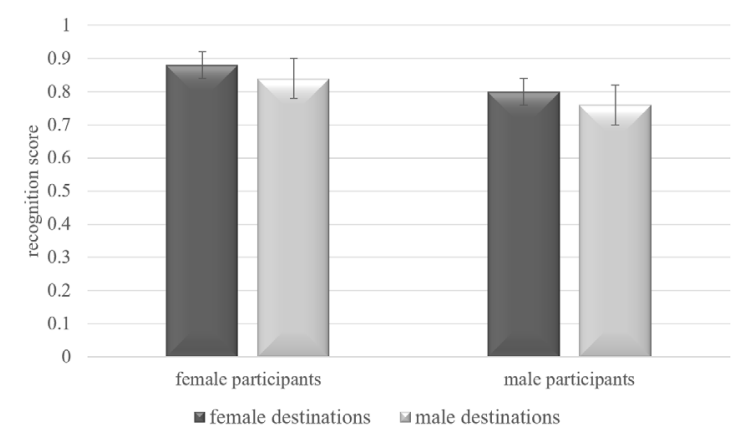

FIGURE 1.

Recognition scores for female and male destinations in female and male participants. Error bars represent intervals of $95 \%$ within-subject confidence. 
outperform males when the memory material is verbal (Astur et al., 1998; Lewin et al., 2001; Ruff et al., 1989; Ullman et al., 2008). This advantage is illustrated by a study in which females and males were tested on a series of tasks involving the recall and recognition of verbal material, faces, and abstract pictorial stimuli (Herlitz \& Yonker, 2002). The study found that, regardless of intelligence level, females outperformed males in memorizing verbal materials and faces. The superiority of females in verbal processing has also been observed for autobiographical memories, that is, events that are personally relevant (Luchetti \& Sutin, 2016). Research has demonstrated that females often verbally describe autobiographical events in greater detail (Nahari \& Pazuelo, 2015), higher elaborated construction (Grysman, 2017), and even with more emotional utterances (Grysman, Merrill, et al., 2016). This emotional expressivity can be influenced by endogenous levels of sex hormones (Wassell et al., 2015). Since our task involved processing verbal information (i.e., the proverbs), this may explain the general better destination memory in the female participants.

The superiority of females in destination memory can also be attributed to the fact that they had to process the destination faces. Face processing has been found to be better in females (Herlitz \& Lovén, 2013; McBain et al., 2009; Rehnman \& Herlitz, 2007). From a social perspective, the superiority of females in destination memory could be because females show a greater interest in the social aspects of daily life (Sommer et al., 2013; Su et al., 2009). Finally, and most likely, the superiority of females in destination memory can be attributed to the general superiority of females on verbal episodic memory. This assumption can be supported by the performances of our female participants on Grober and Buschke's (1987) verbal memory task, a performance that was significantly correlated with their general destination memory. Also, and as demonstrated in the ANCOVA results, the effect of participant gender on destination memory increased after controlling for verbal episodic memory, further supporting the effect of verbal episodic memory on gender differences in destination memory.

Although our female participants demonstrated better general destination memory, a similar performance was observed for female and male destinations. In other words, female participants did not demonstrate an own-gender bias, nor did male participants. It hence seems that females and males demonstrate no preference for destination gender. Speculatively, remembering both female and male destinations is important as in everyday life we usually interact with people of both genders, such as family members, friends, and colleagues. From an evolutionary perspective, deficits in associating information with a gender may compromise both basic survival needs (e.g., finding a mate) and secondary gains (e.g., successful professional collaborations with a given gender). In other words, successful daily interactions require remembering one's interlocutors regardless of their gender; otherwise valuable personal and social needs are compromised.

Our evolutionary hypothesis can be embedded in a larger evolutionary model providing a theory for predicting when and where to expect gender similarities or dissimilarities (Buss, 1995; Buss \& Schmitt, 2011). According to this model, while women and men differ in domains in which they face different adaptive problems (e.g., solu- tions to the problem of commitment in long-term relationships), they are similar in all domains in which they face similar adaptive problems. Buss and Schmitt (2011) suggest that similarities between women and men outnumber their dissimilarities. For instance, these similarities include those related to habitat preferences (e.g., for resource-rich environments containing places for refuge), and adaptations to avoid dangerous forces of nature. These similarities may also be observed for mating as women and men face many similar adaptive problems. For example, both genders face the problem of identifying mates who will commit to them (Buss \& Schmitt, 1993). This evolutionary model is important because it emphasizes similarities between women and men. Building on this model, we propose that, although women demonstrate high destination memory, women and men do not demonstrate a destination-related own-gender bias because both women and men may need to retain the destination to fulfill basic survival needs (e.g., finding a mate) and/or secondary gains (e.g., successful professional collaborations with a given gender).

One limitation of our study was the absence of a control face recognition task. Such a task would have been important for controlling whether better destination memory in our female participants was related to their face-processing ability. Another limitation of our study may be the lack of assessment of cognitive functions such as working memory, executive function, or visuospatial and verbal skills. This assessment would be important to check for gender differences or similarities in functions involved in destination memory, or simply in basic cognitive abilities.

To summarize, information is constantly relayed to family members, colleagues, friends, and/or strangers in daily life, so the ability to associate specific relayed information to an interlocutor (i.e., destination memory) is essential for communicative efficacy. Our study shows that females are more capable of remembering to whom they previously told information. However, no difference was found regarding destination gender. This suggests that females not only have better verbal episodic memory performance but also a significantly better ability to process interlocutors in social interactions.

\section{ACKNOWLEDGEMENTS}

This research did not receive any specific grant from funding agencies in the public, commercial, or not-for-profit sectors. The authors declare no conflict of interest

\section{REFERENCES}

Astur, R. S., Ortiz, M. L., \& Sutherland, R. J. (1998). A characterization of performance by men and women in a virtual Morris water task: A large and reliable sex difference. Behavioral Brain Research, 93, 185-190. doi: 10.1016/S0166-4328(98)00019-9

Buss, D. M. (1995). Psychological sex differences: Origins through sexual selection. American Psychologist, 50, 164-168. doi:

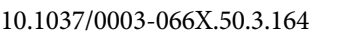

Buss, D. M., \& Schmitt, D. P. (1993). Sexual strategies theory: An evolutionary perspective on human mating. Psychological Review, 100, 204-232. سلس 
Buss, D. M., \& Schmitt, D. P. (2011). Evolutionary psychology and feminism. Sex Roles, 64, 768. doi: 10.1007/s11199-011-9987-3 المالسلس

Cornoldi, C., \& Vecchi, T. (2004). Visuo-spatial working memory and individual differences. Psychology Press.

Cross, J. F., Cross, J., \& Daly, J. (1971). Sex, race, age, and beauty as factors in recognition of faces. Perception and Psychophysics, 10, 393-396. doi: 10.3758/bf03210319 السلسلسلس

El Haj, M. (2017). Stereotypes influence destination memory in normal aging. Experimental Aging Research, 43, 355-366. doi: 10.1080/0361073X.2017.1333821 إلسلس

El Haj, M., Allain, P., \& Kessels, R. P. (2014). The cognitive and neuroanatomical underpinnings of destination memory. Translational Neuroscience, 5, 147-151. doi: 10.2478/s13380-014-0219-5 الالسلالسا

El Haj, M., Fasotti, L., \& Allain, P. (2015). Destination memory for emotional information in older adults. Experimental Aging Research, 41, 204-219. doi: 10.1080/0361073X.2015.1001658 السلسلس

El Haj, M., Kessels, R. P., Matton, C., Bacquet, J. E., Urso, L., Cool, G., . .. Antoine, P. (2016). Destination memory in Korsakoff's syndrome. Alcoholism: Clinical and Experimental Research, 40, 1321-1327. doi: 10.1111/acer.13070 المسلسلس

El Haj, M., \& Miller, R. (2018). Destination memory: The relationship between memory and social cognition. Psychological Research, 82, 1027-1038. doi: 10.1007/s00426-017-0891-5 المسلسلس

El Haj, M., Omigie, D., \& Samson, S. (2015). Destination memory and familiarity: Better memory for conversations with Elvis Presley than with unknown people. Aging Clinical and Experimental Research, 27, 337-344. doi: 10.1007/s40520-014-0286-z السلسلسلس

El Haj, M., Raffard, S., Antoine, P., \& Gely-Nargeot, M. C. (2015). Emotion and destination memory in Alzheimer's disease. Current Alzheimer Research, 12, 796-801. Wس

Ellis, H., Shepherd, J., \& Bruce, A. (1973). The effects of age and sex upon adolescents' recognition of faces. The Journal of Genetic Psychology, 123, 173-174. doi: 10.1080/00221325.1973.10533202 المالسلس

Fivush, R. (2011). The development of autobiographical memory. Annual Review of Psychology, 62, 559-582. doi: 10.1146/annurev. psych.121208.131702 المسلسلس

Fivush, R., Habermas, T., Waters, T. E., \& Zaman, W. (2011). The making of autobiographical memory: Intersections of culture, narratives and identity. International Journal of Psychology, 46, 321-345. doi: 10.1080/00207594.2011.596541 الميلسلسلس

Fivush, R., \& Nelson, K. (2004). Culture and language in the emergence of autobiographical memory. Psychological Science, 15, 573-577. doi: 10.1111/j.0956-7976.2004.00722.x الس السلس

Gopie, N., Craik, F. I., \& Hasher, L. (2010). Destination memory impairment in older people. Psychology and Aging, 25, 922-928. doi: 10.1037/a0019703 1لس

Gopie, N., \& MacLeod, C. M. (2009). Destination memory: Stop me if I've told you this before. Psychological Science, 20, 1492-1499. doi: 10.1111/j.1467-9280.2009.02472.x المالسلس (1987)

Grober, E., \& Buschke, H. (1987). Genuine memory deficits in dementia. Developmental Neuropsychology, 3, 13-36. doi: 10.1080/87565648709540361 الملسلة
Grysman, A. (2017). Gender differences in episodic encoding of autobiographical memory. Journal of Applied Research in Memory and Cognition, 6, 51-59. doi: http://dx.doi.org/10.1016/j.jarmac.2016.07.012 एلس

Grysman, A., Fivush, R., Merrill, N. A., \& Graci, M. (2016). The influence of gender and gender typicality on autobiographical memory across event types and age groups. Memory and Cognition, 44, 856-868. doi: 10.3758/s13421-016-0610-2

Grysman, A., Merrill, N., \& Fivush, R. (2016). Emotion, gender, and gender typical identity in autobiographical memory. Memory, 3, 289-297. doi: 10.1080/09658211.2016.1168847 البلسلسلسا

Herlitz, A., \& Lovén, J. (2013). Sex differences and the own-gender bias in face recognition: A meta-analytic review. Visual Cognition, 21, 1306-1336. doi: 10.1080/13506285.2013.823140 البلسلسلكا

Herlitz, A., \& Yonker, J. E. (2002). Sex differences in episodic memory: The influence of intelligence. Journal of Clinical and Experimenatl

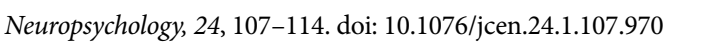
Lewin, C., Wolgers, G., \& Herlitz, A. (2001). Sex differences favoring women in verbal but not in visuospatial episodic memory.

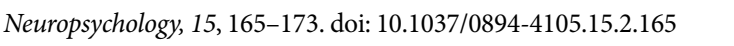

Loven, J., Herlitz, A., \& Rehnman, J. (2011). Women's own-gender bias in face recognition memory. Experimental Psychology, 58, 333-340. doi: 10.1027/1618-3169/a000100 كلالس

Luchetti, M., \& Sutin, A. R. (2016). Measuring the phenomenology of autobiographical memory: A short form of the Memory Experiences Questionnaire. Memory, 24, 592-602. doi: 10.1080/09658211.2015.1031679 البلسلة

McBain, R., Norton, D., \& Chen, Y. (2009). Females excel at basic face perception. Acta Psychologica, 130, 168-173. doi: 10.1016/j. actpsy.2008.12.005 إسلس

Megreya, A. M., Bindemann, M., \& Havard, C. (2011). Sex differences in unfamiliar face identification: evidence from matching tasks. Acta Psychologica, 137, 83-89. doi: 10.1016/j.actpsy.2011.03.003 المالسلساس

Munoz-Montoya, F., Fidalgo, C., Juan, M.-C., \& Mendez-Lopez, M. (2019). Memory for object location in augmented reality: The role of gender and the relationship among spatial and anxiety outcomes. Frontiers in Human Neuroscience, 13, 113. doi: 10.3389/ fnhum.2019.00113

Nahari, G., \& Pazuelo, M. (2015). Telling a convincing story: Richness in detail as a function of gender and information. Journal of Applied Research in Memory and Cognition, 4, 363-367. doi: 10.1016/j.jar-

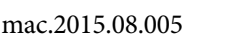

Rehnman, J., \& Herlitz, A. (2006). Higher face recognition ability in girls: Magnified by own-sex and own-ethnicity bias. Memory, 14, 289-296. doi: 10.1080/09658210500233581 Ш山ل|

Rehnman, J., \& Herlitz, A. (2007). Women remember more faces than men do. Acta Psychologica, 124, 344-355. doi: 10.1016/j.actpsy.2006.04.004 السلس

Ruff, R. M., Light, R. H., \& Quayhagen, M. (1989). Selective Reminding Tests: A normative study of verbal learning in adults. Journal of Clinical and Experimental Neuropsychology, 11, 539-550. doi: 10.1080/01688638908400912 السلسلس 
Sherman, A. M., de Vries, B., \& Lansford, J. E. (2000). Friendship in childhood and adulthood: Lessons across the life span. The International Journal of Aging and Human Development, 51, 31-51. doi: 10.2190/4QFV-D52D-TPYP-RLM6 الف السلس

Snodgrass, J. G., \& Corwin, J. (1988). Pragmatics of measuring recognition memory: Applications to dementia and amnesia. Journal of Experimental Psychology: General, 117, 34-50. doi: 10.1037/00963445.117.1.34 سلس

Sommer, W., Hildebrandt, A., Kunina-Habenicht, O., Schacht, A., \& Wilhelm, O. (2013). Sex differences in face cognition. Acta Psychologica, 142, 62-73. doi: 10.1016/j.actpsy.2012.11.001 السلسلسل

Steffens, M. C., Landmann, S., \& Mecklenbrauker, S. (2013). Participant sexual orientation matters: New evidence on the gender bias in face recognition. Experimental Psychology, 60, 362-367. doi: 10.1027/1618-3169/a000209 الم

Su, R., Rounds, J., \& Armstrong, P. I. (2009). Men and things, women and people: a meta-analysis of sex differences in interests. Psychological Bulletin, 135, 859-884. doi: 10.1037/a0017364 السلسلسل|
Ullman, M. T., Miranda, R. A., \& Travers, M. L. (2008). Sex differences in the neurocognition of language. In J. B. Becker, K. J. Berklry, N. Geary, E. Hampson, J. P. Herman \& E. A. Young (Eds.), Sex differences in the brain from genes to behavior (pp. 291-309). Oxford University Press.

Van der Linden, M., Adam, S., Agniel, A., Baisset- Mouly, C., Bardet, F., \& Coyette, F. (2004). L'évaluation des troubles de la mémoire: Présentation de quatre tests de mémoire épisodique (avec leur étalonnage) [Evaluation of memory deficits: Presentation of four tests of episodic memory (with standardization)]. Solal Editeurs.

Wassell, J., Rogers, S., Felmingam, K. L., Pearson, J., \& Bryant, R. A. (2015). Progesterone and mental imagery interactively predict emotional memories. Psychoneuroendocrinology, 51, 1-10. doi: 10.1016/j.psyneuen.2014.09.005 اله السلسل

Wright, D. B., \& Sladden, B. (2003). An own gender bias and the importance of hair in face recognition. Acta Psychologica, 114, 101-114. |ل|سل| 